\title{
Large uncomplicated hydropneumopericardium
}

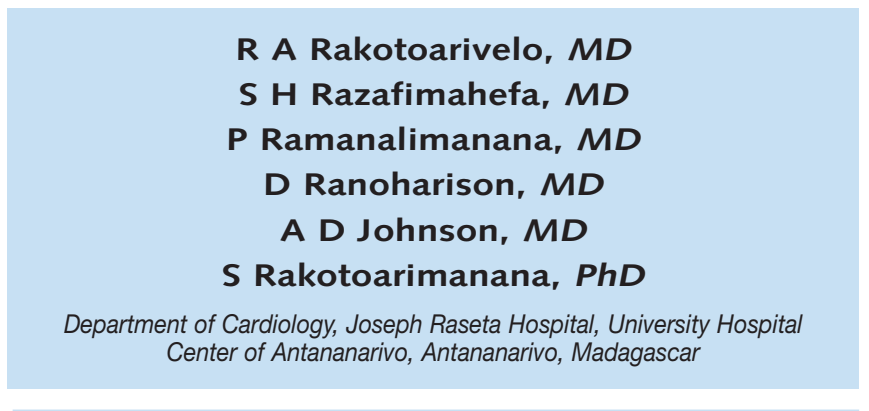

A 45-year-old Malagasy man, with a 2-month medical history of chronic pericarditis, presented to the Department of Cardiology at Joseph Raseta Hospital with cardiac tamponade. Pericardiocentesis was performed, with improvement in the patient's clinical condition, following aspiration of $400 \mathrm{cc}$ of serofibrinous fluid. The control chest X-ray revealed a hydropneumopericardium (Figs 1a and 1b). Following evaluation of the fluid, tuberculosis treatment was started with an adjunctive corticosteroid régimen and resultant complete resolution of all cardiac symptoms.

The diagnosis of hydropneumopericardium requires the application of Shackelford criteria which include (i) high-pitched tympanic percussion note, (ii) loud metallic splashing sound synchronous with heart sounds, and (iii) characteristic chest X-ray with an air-fluid level in the pericardial cavity. ${ }^{1}$
Traumatic origins of hydropneumopericardium are more common than non-traumatic causes. Non-traumatic causes of hydropneumopericardium include asthma, gastro-pericardic fistula complicating gastric pathology, and infectious disease from illnesses such as pericarditis and pneumonia. Traumatic causes are many and varied, including chest trauma (11\%) and iatrogenic causes (74\%), particularly those arising after mechanical ventilation, cardiac surgery, and pace-maker implantation. ${ }^{2}$ Pericardiocentesis is the cornerstone of the management of cardiac tamponade. Kabukcu has performed 50 such procedures safely. ${ }^{3}$ There are few reports of pneumopericardium linked to pericardic drainage. ${ }^{4}$

Cardiac tamponade is encountered in $37.7 \%$ of pneumopericardium cases. $^{2}$ Although its occurrence is not dependent upon the quantity of air in the pericardic cavity, spontaneous remission has been documented in the case of a small pneumopericardium. ${ }^{5}$

1. Shackelford RT. Hydropneumopericardium. JAMA 1931; 96: 187-191.

2. Wu M, He X, Yang G. Spontaneous tension hydropneumopericardium complicating serofibrinous pericarditis. Eur J Cardiothorac Surg 2006; 29: 422-424.

3. Kabukcu M, Demircioglu F, Yanik E, Basarici I, Ersel F. Pericardial tamponade and large pericardial effusion: causal and efficacy of percutaneous catheter drainage in 50 patients. Heart Inst J 2004; 31: 398-403. 4. Gan H, Simpson JM. Pneumopericardium presenting as reduced ECG voltages. Heart 2005; 91: 298. 5. Levin S, Maldonado I, Rehm C, Ross S, Weiss R. Cardiac tamponade without pericardial effusion after blunt chest trauma. Am Heart J 1996; 131: 198-200.
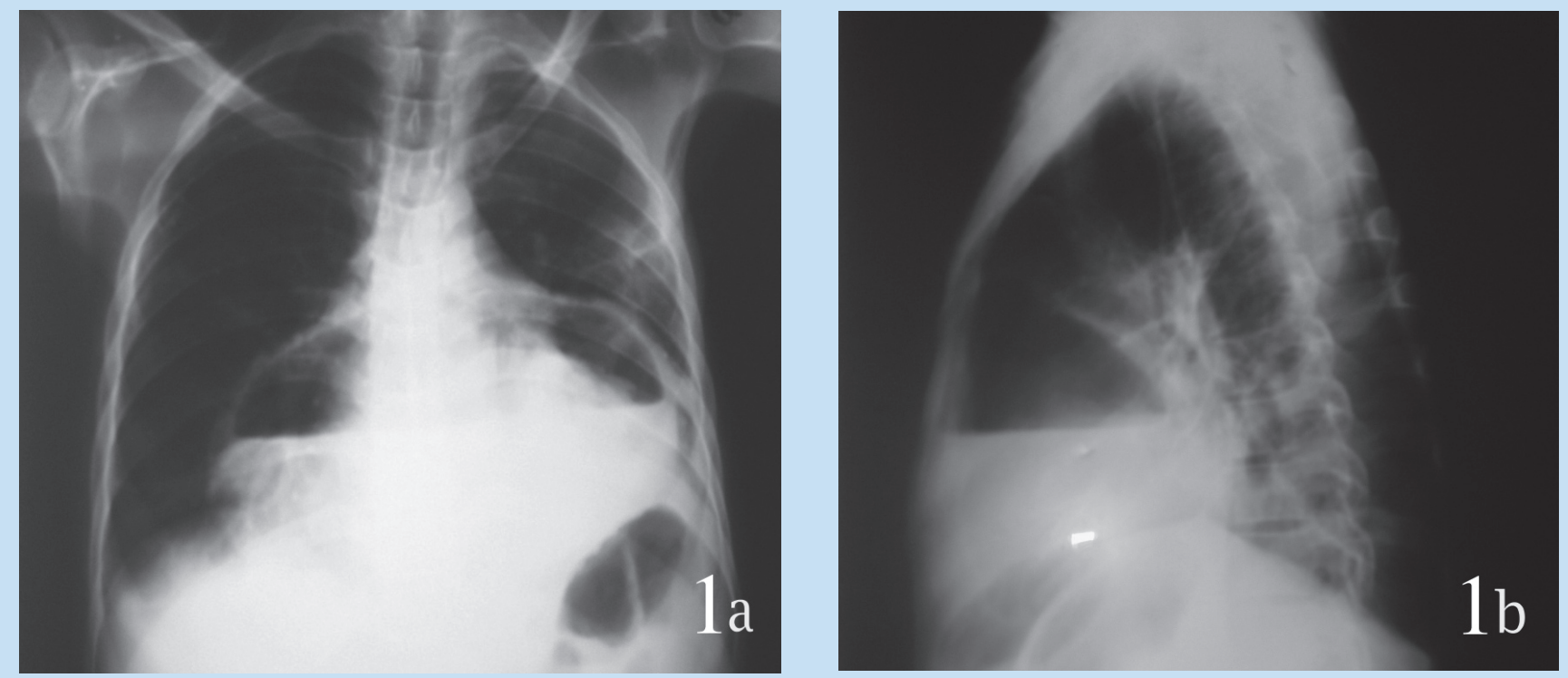

Fig. 1a and b. Chest X-ray after pericardiocentesis. Hydropneumopericardium showing air/fluid level: frontal view (a) and side view (b). 